\title{
Власть, общество, эксперты - трансформация связей в эпоху цифровых технологий
}

\author{
Л. В. Шиповалова \\ Санкт-Петербургский государственный университет \\ l.shipovalova@spbu.ru
}

\section{Аннотация}

Экспертное знание является значимым элементом взаимодействия власти и общества в контексте необходимости принятия решений в поле управления. Отношения между тремя элементами этих взаимодействий складываются неоднозначно. В статье рассматривается возможность решения проблемы автономии научных исследований в контексте практик публичной научной коммуникации, конкретнее, в контексте взаимоотношения экспертов, публики и власти. В качестве концептуального основания предлагается использовать модели коммуникации экспертов и власти, описываемые Ю. Хабермасом, среди которых прагматическая модель оказывается перспективной, но недостаточно обоснованной.

Автор предлагает произвести конкретизацию данной модели посредством дополнения ее концептом упреждающего управления. Кроме того, цифровые технологии рассматриваются автором не только как средство упреждающего управления, но и как его объект. В статье выдвигается и предварительным образом обосновывается тезис о том, что дизайн упреждающего управления, направленного на цифровые технологии, не только способствует организации диалога научных экспертов, публики и власти, но может служить автономии научных исследований. Предложенный концептуальный синтез прагматической модели взаимодействия экспертов и власти, упреждающего управления и цифровых технологий рассматривается на примере обсуждения применения цифровых технологий в голосовании по значимым социальнополитическим проблемам в России. В статье делается вывод о конструктивности такого синтеза относительно практического выявления ситуаций провалов управляемости и сотрудничества различных субъектов управления.

Ключевые слова: публика, эксперты, цифровые технологии, упреждающее управление

Библиографическая ссылка: Шиповалова Л.В. Власть, общество, эксперты трансформация связей в эпоху цифровых технологий // Государство и граждане в электронной среде. Выпуск 4 (Труды XXIII Международной объединенной научной конференции «Интернет и современное общество», IMS-2020, Санкт-Петербург, 17 20 июня 2020 г. Сборник научных статей). - СПб: Университет ИТМО, 2020. С. 11-19. DOI: $10.17586 / 2541-979 X-4-11-19$

\section{1. Введение}

Контекстом, определяющим значимость данной темы, может считаться проблема автономии научных исследований, оказывающаяся актуальной после так называемой научно-технической революции. Это событие, датируемое историками науки первой половиной XX века, приводит к тому, что наука, ориентированная на инновационную практику, становится несомненной общественной силой и, как следствие, объектом политического управления. Указанные процессы во второй половине XX века приводят к 
появлению концепта технонауки, который фиксирует с одной стороны неотделимость науки от совершенствования технологий и, с другой, ее ориентацию по преимуществу на результативность и эффективность, на выполнение требований, предъявляемых властью, исходящих из локальных и глобальных интересов [1]. В контексте такой ориентации научное исследование становится не просто орудием политики, но и способом ее легитимации, превращаясь в идеологию. Новая идеология оказывается едва ли не более влиятельной, чем та, которой она приходит на замену. В отличие от классической, исходящей из придания частным интересам всеобщего характера, современная научная идеология включает в себя критику субъективности и, выступая от имени всеобщих объективных законов, претендует на непререкаемую власть, обеспеченную силой научнотехнологического разума $[2 ; 3$, p. 650]. Так возникает проблема автономии научных исследований, состоящая в том, что с одной стороны «онаученная политика» охраняет служащее ей научное знание от возможной критики со стороны общественного мнения, и, с другой, расплатой за это сохранение элитарной позиции научного знания оказывается его подчинение интересам власти, к какой бы сфере они не относились. Эта проблема автономии науки от политики перестает быть частной проблемой научного сообщества, поскольку еe c необходимостью сопровождает исключение или амбивалентная желательность включения непрофессионалов, публики в чаще всего закрытое взаимодействие ученых и субъектов власти, а также в дискуссии вокруг значимых общественных вопросов. Возможности решения этой проблемы или условия ее сохранения лежат в области публичной научной коммуникации. В статье будут рассмотрены некоторые аспекты публичной научной коммуникации, в которых может формироваться автономия науки. В фокусе окажется современная ситуация, связанная с использованием цифровых технологий в поле публичной политики.

\section{2. Роль экспертов в научной коммуникации с властью}

Коммуникация научного сообщества и управляющих обществом субъектов реализуется опосредованно. Не всякое научное исследование может иметь непосредственно применимые результаты; не всякое научное знание сопровождается в своем получении, распространении и применении деятельностью, посредством которой оно связывается с властью. Для того чтобы стать практически-ориентированным, научному знанию необходим «перевод», обнаруживающий в теоретических высказываниях способы их аппликации или выявляющий пути изменения реальности в соответствии с теоретическими представлениями [4]. Такой перевод реализуется субъектами научного знания, выступающими в роли экспертов. То есть экспертное знание всегда связано с обсуждением практических задач и представляет собой трансляцию теоретического знания в поле возможного принятия общественно значимых решений [5]. И, хотя в дальнейшем обсуждении стратегий коммуникации экспертов, власти и публики речь будет идти об экспертах как о самостоятельных представителях научного сообщества, следует подчеркнуть их посредническую роль. Это акцентирование посреднической роли экспертов или экспертного знания значимо в двух аспектах. Во-первых, эксперты, их деятельность и знание, представляют собой своего рода границу между научным теоретическим знанием и его использованием политическими субъектами. Если такой границы нет, если экспертное практическое знание отождествляется с научным знанием в широком смысле слова, включающим и теорию, возникает соблазн и опасность использования такого знания в целях, нарушающих права человека. Возможность такого использования обусловлена объединением в этом случае однозначного характера практического знания и непререкаемого авторитета науки, подтверждающего его достоверность.

В таком положении была, например, расовая теория как практическое, но одновременно претендующее на теоретическую обоснованность знание, придавшая нацизму его научный характер [6, с. 96-104]. Различие же экспертного знания и научного теоретического, 
подчеркивание посреднической функции экспертов, заставляет воспринимать научное теоретическое знание как открытое критике и не окончательное. Во-вторых, посредническая роль делает научных экспертов важной фигурой ответственности в процессах выработки и принятия политических решений и подчеркивает то, что в выполнении этой роли эксперт оказывается на пересечении различных общественных интересов. Эта роль включает эксперта в поле ответственности за решение проблемы автономии научных исследований, а также ставит вопрос о его объективности и нейтральности, неоднократно звучащий в последнее время, в том числе в пространстве отечественных дискуссий $[7 ; 8]$.

При рассмотрении неоднозначной роли экспертов, включающихся во взаимодействие науки и общества, оказывающихся так или иначе связанных с властью, мы обратимся к различению способов связи субъектов власти, экспертов и публики, которые описывает Ю. Хабермас, проблематизируя возможности демократии в условиях «онаученной политики» [9]. Хабермас выделает, во-первых, децизионистскую модель, в которой принимающий решения политик использует экспертное знание, но не подчиняется ему, реализуя принятием решения собственное понимание конкретной ситуации и осуществляя ответственный выбор «между конкурирующими ценностными порядками». Во-вторых, актуальной оказывается технократическая модель собственно «онаученной политики», где практическое действие полностью следует технологической рациональности, учреждаемой как единственно возможная. В-третьих, существует прагматическая модель, предполагающая диалог, взаимное обогащение и коррекцию практических общественных целей, осуществляемых решением политика, и научных рекомендаций, обсуждающих возможность этих общественных целей и разрабатывающих стратегии их актуализации. Первые две модели ставят под вопрос демократическое общественное устройство, поскольку либо, в контексте реализации децизионистской модели, заставляют публику, допускаемую только к выборам субъектов власти, но не к обсуждению содержания их решений, исключительно легитимировать существующее управление. Либо, в случае реализации отношений в соответствии с технократической моделью, подчиняют общественное мнение диктату научно-технической рациональности, предъявляемой в качестве необходимой и единственно возможной. Также в этих двух случаях оказывается проблематичной и автономия науки, если понимать под ней следование всеобщему интересу, а не подчинение определенной властной интенции. Третья модель, описываемая философами прагматической ориентации, представляется Хабермасу недостаточно разработанной и не конструктивной в современных ему условиях, когда следует говорить скорее о принципиальном отсутствии оснований для диалога субъектов власти и экспертов. Однако следует заметить, что изменяющаяся ситуация, связанная, с использованием цифровых технологий в публичном пространстве, в процессах управления, а также с таким специфическим дизайном управления как упреждающее управление, делает эту прагматическую модель актуальной и возможно более реализуемой.

\section{3. Упреждающее управление и цифровые технологии}

Нам представляется, что такая форма связи субъектов власти, научного сообщества (экспертов как посредников) и непрофессиональной публики как упреждающее управление (anticipatory governance) оказывается способом конкретного наполнения содержанием абстрактной прагматической модели, о которой как верной принципам демократии пишет Хабермас. Кроме того, именно эта форма может быть проинтерпретирована как путь к разрешению проблемы автономии науки, разрывающий однозначные идеологические отношения с властью. Под упреждающим управлением мы будем понимать, следуя исследованиям в области STS (Science, Technology, Society), практики управления и самоуправления, распределенные между различными общественными субъектами, реализуемые с использованием различных инструментов и имеющие в фокусе обсуждения 
и принятия решения новые технологии, основанные на знании [10]. Целью упреждающего управления является предотвращение напряженности в обществе, связанной с возможной реакцией граждан на внедрение новых технологий. Организуемые дискуссии могут быть ориентированы на реализацию принципа понятности технологий, формирования доверия к ним со стороны публики, взаимного перевода аргументов и установления локального консенсуса между различными заинтересованными лицами. Именно в этом случае отношение экспертов с властью становится неоднозначным, а автономия науки, реализуемая посредством такой экспертной деятельности, возможной.

Существенным в апелляции к такому дизайну управления является для нас то, что он может служить делигитимации или религитимации классических институтов управления, переводу их в форму институтов управляемости [11]. В этом случае с необходимостью вводится в практики принятия решений публика как субъект переговоров и значимый фактор общественных действий и сотрудничества. Способы участия публики в процессах управляемости многообразны, однако объединены они характером события распределенного познания, властный центр которого не задан априори, а формируется (причем не обязательно и не всегда) в результате конкретных коммуникативных практик [12]. Примером таких событий могут служить различного рода сетевые дискуссии, организованные субъектами власти или самоорганизующиеся, предметом которых оказываются новые технологии, обладающие возможностью существенного воздействия на всех членов общества, а также потенциально допускающие нарушение прав человека и выход за границы общественного контроля. Начало активного использования концепта упреждающего управления в исследованиях коммуникации экспертов, субъектов власти и публики относится к началу XXI века; оно характеризует обсуждения разработок в области нанотехнологий и их возможное применение. В настоящее время этот концепт применяется, в частности, относительно дискуссий о технологиях в области синтетической биологии или о проблемах, связанных с изменением климата [13; 14]. В таких дискуссиях невозможно проигнорировать активную роль экспертов, владеющих знанием о технологиях, способных к «переводу» этого знания для иных заинтересованных лиц, делающих технологии «понятными» как публике, так и использующим их властным субъектам.

Второй важной характеристикой изменяющейся ситуации, позволяющей реализоваться прагматической модели, может служить активное использование в публичной сфере цифровых технологий. Они способствуют решению проблемы непосредственного взаимодействия граждан с властью, организации и эффективному функционированию каналов обратной связи в процессах управления [15; 16]. В контексте сказанного выше о первой характеристике, следует отметить, что практики упреждающего управления часто используют цифровые технологи, в частности сбор больших данных в качестве инструмента. Этот механизм как минимум обеспечивает выявление общественного мнения, хотя чистота его результата достаточно проблематична. Однако нас интересует ситуация, когда цифровые технологии оказываются не просто орудием упреждающего управления, но оказываются объектом регулирования и обсуждения. Повсеместное использование цифровых технологий, которые, безусловно, следует считать также технологиями, основанными на знании, в практиках принятия решений, в том числе в общественных переговорах и даже в процессах осуществления власти, делает актуальным вопрос о возможности использования их в целях нарушения прав человека и выводе их за границы общественного контроля. В этом смысле цифровые технологии, не меньше, чем биотехнологии или нанотехнологии производят потенциальное воздействие на всех членов общества, а также могут делать это общество пассивным объектом манипулирования и неконтролируемой трансформации. В зарубежной литературе недавно появились исследования, относящиеся к применению концепта упреждающего управления к цифровым технологиям как объекту [17], однако поскольку данное применение всегда ситуационно, мы считаем актуальным подобное рассмотрение и в отечественном контексте, что, насколько нам известно, не производилось до настоящего времени. 
Подчеркнем один момент, демонстрирующий конструктивность соединения концепта упреждающего управления и цифровых технологий в качестве его объекта в контексте поставленной нами проблемы автономии науки в ее отношениях с властью. Дело в том, что в дизайне упреждающего управления существенна его принципиальная рефлексивность. В его практики, по крайней мере, в тех случаях, которые уже были реализованы, включены социальные исследования, критически рассматривающие те черты упреждающего управления, которые представляют опасность для его адекватной реализации. Среди таких черт существенными являются следующие: неопределенность объекта обсуждения (технологии, предполагаемой к внедрению), наивность включаемой и включающейся в обсуждения публики, а также поддержка властью амбиций технонауки [10]. Если эти черты не попадают в поле критической рефлексии, они способствуют консервации проблемы автономии научных исследований и препятствуют демократическим процессам. Напротив, осознанная работа с ними, может служить как разрешению указанной проблемы, так и демократии. Если эти черты обнаруживаются и оказываются предметом преодоления, появляется надежда на совершенствование, как самого упреждающего управления, так и практик публичной политики в широком смысле слова.

В отечественном поле публичной политики можно обнаружить актуальные ситуации, в которых цифровые технологии оказываются инструментом, а также объектом упреждающего управления. Официальные цифровые платформы предлагаются субъектами власти с целью вовлечения граждан в управление и оказываются инструментом организации участия. В частности, речь может идти о формировании условий активности граждан, принимающих участие в управлении городом с использованием цифровых платформ на примере работы платформы «Активный гражданин». Одна из программ, реализуемых посредством этой платформы и затрагивающих интересы большого количества граждан, - это Программа реновации жилья в Москве (2017 г.). В настоящий момент ситуация с этой программой обретает особую актуальность, поскольку в связи с пандемией COVID-19 не только голосования по частным вопросам, но и все обсуждения, которые ранее проходили в оффлайн формате, были перенесены на эту платформу. Такое привлечение к участию граждан первоначально можно было только условно назвать упреждающим управлением: оно было не таковым по объекту, которым не являлись непосредственно технологии, основанные на знании. Однако по целям (предотвращение общественной напряженности) и по средствам (цифровые технологии в виде официальных платформ и социальных сетей) его можно было сразу назвать таковым. В процессе же осуществления такие практики вовлечения граждан постепенно становятся упреждающим управлением в полном смысле слова, поскольку в фокус дискуссий власти, граждан и экспертов попадает также вопрос о доверии самим цифровым технологиям, в частности, доверии предлагаемой властью для обсуждения и голосования цифровой платформе.

Следует сразу отметить, что непосредственных дискуссий экспертов и публики относительно процедур электронного обсуждения по Программе реновации не было обнаружено в ведущих СМИ, имеющих в фокусе информационные технологии (анализ за последний год самых цитируемых СМИ отраслей IT [18]). При этом на сайте Activatica.org были обнаружены сомнения в конструктивности такого рода обсуждения, что позволяет констатировать определенную напряженность вокруг данной ситуации [19]. Поскольку в данном случае речь идет об использовании блокчейн-технологий, посредством которых реализуется голосование на платформе «Активный гражданин», оказалось рациональным обратиться к экспертному обсуждению именно этого вопроса. В этом контексте были обнаружены две важные тенденции, относящиеся, на наш взгляд, к практикам упреждающего управления. Во-первых, речь идет о признании экспертами необходимости актуализации интереса граждан к новым технологиям голосования и доверия им [20]. В этом случае важным элементом формирования доверия оказывается то, что эксперты не только отмечают плюсы данных технологий, но и открыто обсуждают конкретные проблемы их функционирования в России, уязвимости и сбои в их работе [20; 21]. Во-вторых, имеет 
место своего рода стратегия популяризации, раскрывающая принципы работы данных технологий, делающих их «понятными» публике [22]. Эти тенденции могут быть проинтерпретированы как конструктивный ответ на проблемы упреждающего управления, связанные, как это было отмечено выше, с неопределенностью в действии обсуждаемых технологий и дилетантизмом включаемой в обсуждения публики. Кроме того, эти тенденции демонстрируют определенное «расцепление» экспертного знания и власти, поскольку они связаны с необходимостью согласования интересов различных участников процессов управления, в том числе интересов публики, не всегда доверяющей цифровым технологиям голосования.

\section{4. Заключение}

В статье была рассмотрены возможности решения проблемы автономии научных исследований в контексте практик публичной научной коммуникации. В качестве концептуального основания было предложено использовать модели коммуникации экспертов и власти, определяемые Ю. Хабермасом, среди которых прагматическая модель называется им перспективной, но недостаточно обоснованной. Нам представляется, что этой модели может быть дана необходимая конкретизация дополнением ее посредством концептов упреждающего управления и цифровых технологий. Причем цифровые технологии должны быть рассмотрены не только как средство упреждающего управления, но и как его объект. В статье был выдвинут и предварительным образом обоснован тезис о том, что дизайн упреждающего управления, направленного на цифровые технологии, способствует не только организации взаимодействия научных экспертных рекомендаций, политических целей и общественных ожиданий, но и может служить автономии научных исследований. Предложенный концептуальный синтез прагматической модели взаимодействия экспертов, публики и власти, упреждающего управления и цифровых технологий конструктивен относительно практического выявления ситуаций провалов управляемости и сотрудничества различных субъектов управления. В отечественном контексте, такой синтез актуален в ситуациях дискуссий относительно использования цифровых технологий для обсуждений и голосований по значимым социальнополитическим вопросам. В этом случае он имеет и перспективы исследования, к которым следует отнести, в частности, подтверждение влияния профессиональных экспертных высказываний на активность участия граждан в управлении посредством цифровых платформ.

Работа выполнена при поддержке Российского научного фонда, грант № 19-18-00210 «Политическая онтология цифровизации: исследование институциональных оснований цифровых форматов государственной управляемости».

\section{Литература}

[1] Кошовец О.Б., Фролов И.Э. «Прекрасный новый мир»: о трансформации науки в технонауку // Эпистемология и философия науки. 2020. Т. 57, № 1. С. 20-31.

[2] Хабермас Ю. Технический прогресс и социальный мир // Ю. Хабермас техника и наука как «идеология». М.: Праксис. 2007. С. 117-135.

[3] Feenberg A. A Critical Theory of Technology // Handbook on Science and Technology Studies. U. Felt, R. Fouché, C.A. Miller, L. Smith-Doerr. Cambridge, (eds.) MA: MIT Press. 2017. P. 635-664.

[4] Grundmann R. The Problem of Expertise in Knowledge Societies // Minerva. 2017. Vol. 55. P. 25-48. 
[5] Peters H.P. Scientists as public experts: expectations and responsibilities. // Routledge Handbook of Public Communication of Science and Technology / ed. by M. Bucchi, B. Trench. London and New York: Routledge, Taylor \& Francis Group. 2014. P. 70-82.

[6] Грундманн Р. Штер Н. Власть научного знания. СПб.: Алетейя, 2015. 324 с.

[7] Nisbet N.C. Engaging in science policy controversies: insights from the US climate change debate // Routledge Handbook of Public Communication of Science and Technology / ed. by M. Bucchi, B. Trench. London and New York: Routledge, Taylor \& Francis Group. 2014. P. 173-185.

[8] Сунгуров А.Ю. Фабрики мысли и экспертное сообщество в Москве, Санкт-Петербурге, Нижнем Новгороде и на Северном Кавказе // Политическая концептология: журнал междисциплинарных исследований. 2017. № 2. С. 115-137.

[9] Хабермас Ю. Онаученная политика и общественное мнение // Техника и наука как «идеология». М.: Праксис, 2007. С. 136-166.

[10]Guston D. H. Understanding «anticipatory governance» // Social Studies of Science. 2014. Vol. 44, № 2. P. 218-242.

[11]Сморгунов Л.В. Институционализация управляемости и проблема контроля в пространстве цифровых коммуникаций // Южно-российский журнал социальных наук. 2019. T. 20, № 3. C. 62-75.

[12]Hutchins E. The Cultural Ecosystem of Human Cognition // Philosophical Psychology. 2014. Vol. 27, № 1. P. 34-49.

[13]Conca K. Prospects for a multi-stakeholder dialogue on climate engineering // Environmental Politics. 2019. Vol. 28, № 3. P. 417-440.

[14] Ribeiro B., Shapira P. Anticipating governance challenges in synthetic biology: Insights from biosynthetic menthol // Technological Forecasting and Social Change. 2019. № 139. P. 311-320.

[15]Чугунов А.В. Взаимодействие граждан с властью как канал обратной связи в институциональной среде // Власть. 2017. № 10. С. 59-66.

[16]Чугунов А.В. Модель электронного управления как система обратной связи с гражданами в концепции «Умный город» // International Journal of Open Information Technologies. 2018. Vol. 6, № 12. C. 106-113.

[17]Kera D.R Anticipatory policy as a design challenge: Experiments with stakeholders engagement in blockchain and distributed ledger technologies (Conference Paper) // Advances in Intelligent Systems and Computing. 2020. Vol. 1010. P. 87-92.

[18] ТОП-20 самых цитируемых СМИ отраслей IT и Теlecom [ 1 кв. 2020] // Медиалогия. URL: https://www.mlg.ru/ratings/media/sectoral/7377 (дата обращения: 23.05.2020).

[19]Реновация отнимает у жителей Зюзино парк и поднимает народ на бунт // Activatica. URL: http://activatica.org/blogs/view/id/9860. (дата обращения: 23.05.2020).

[20]Эксперты о блокчейне и электронном голосовании // ICT Moscow. 13.09.2019. URL: https://ict.moscow/news/blockchain-moscow (дата обращения: 23.05.2020).

[21]Блокчейн в России: о чем говорят эксперты. // Mindsmith. URL: https://mindsmith.io/blockchain-experts (дата обращения: 23.05.2020)

[22]Поляков К. Как власти Москвы внедряют блокчейн в городские проекты // Rusbase. URL: https://rb.ru/opinion/blockchain-moscow/ (дата обращения: 23.05.2020).

\section{Authority, Society, Experts - Transformation of Communications in the Digital Age}

\section{L.V. Shipovalova}

\section{St. Petersburg State University}

Expert knowledge is a significant element of interaction between authority and society in the context of public policy and decision-making. The relationship between these three elements of public science communication is ambiguous. The article considers the possibility of solving the 
issue of the science autonomy in the context of public science communication, more specifically, in the context of the relationship between experts, public and the authorities. As a conceptual basis, the author proposes to use the models of communication between experts and authorities described by J. Habermas, among whom the pragmatic model turns out to be promising, but insufficiently justified.

The author proposes to specify this model by supplementing it with the concept of anticipatory governance. Moreover, she considers the digital technologies not only as a means of anticipatory governance, but also as its object. The article puts forward the thesis that the design of anticipatory governance aimed at digital technologies not only contributes to the organization of a dialogue between scientific experts, public and the authorities, but can also serve the autonomy of science. The proposed conceptual synthesis of a pragmatic model of interaction between experts, public and authorities, anticipatory governance and digital technologies was considered in the context of discussing the use of digital technologies in voting on significant socio-political issues in Russian Federation. The article concludes that such a synthesis is constructive in relation to the practical identification of failures of governability or cooperation of various actors of public policy.

Keywords: public, experts, digital technologies, anticipatory governance

Reference for citation: Shipovalova L.V. Authority, Society, Experts - Transformation of Communication in the Digital Age // The State and Citizens in the Electronic Environment. Vol. 4 (Proceedings of the XXIII International Joint Scientific Conference «Internet and Modern Society», IMS-2020, St. Petersburg, June 17-20, 2020). - St. Petersburg: ITMO University, 2020. P. 11 - 19. DOI: 10.17586/2541-979X-4-11-19

\section{Reference}

[1] Koshovec O.B., Frolov I.E. «Prekrasnyj novyj mir»: o transformacii nauki v tekhnonauku // Epistemologiya i filosofiya nauki. 2020. T. 57, № 1. S. 20-31. (in Russian).

[2] Habermas YU. Tekhnicheskij progress i social'nyj mir // YU. Habermas tekhnika i nauka kak «ideologiya». M.: Praksis. 2007. S. 117-135. (in Russian).

[3] Feenberg A. A Critical Theory of Technology // Handbook on Science and Technology Studies. U. Felt, R. Fouché, C.A. Miller, L. Smith-Doerr. Cambridge, (eds.) MA: MIT Press. 2017. P. 635-664.

[4] Grundmann R. The Problem of Expertise in Knowledge Societies // Minerva. 2017. Vol. 55. P. 25-48.

[5] Peters H.P. Scientists as public experts: expectations and responsibilities. // Routledge Handbook of Public Communication of Science and Technology / ed. by M. Bucchi, B. Trench. London and New York: Routledge, Taylor \& Francis Group. 2014. P. 70-82.

[6] Grundmann R. SHter N. Vlast' nauchnogo znaniya. SPb.: Aletejya, 2015. 324 s. (in Russian).

[7] Nisbet N.C. Engaging in science policy controversies: insights from the US climate change debate // Routledge Handbook of Public Communication of Science and Technology / ed. by M. Bucchi, B. Trench. London and New York: Routledge, Taylor \& Francis Group. 2014. P. 173-185.

[8] Sungurov A.YU. Fabriki mysli i ekspertnoe soobshchestvo v Moskve, Sankt-Peterburge, Nizhnem Novgorode i na Severnom Kavkaze // Politicheskaya konceptologiya: zhurnal mezhdisciplinarnyh issledovanij. 2017. № 2. S. 115-137. (in Russian).

[9] Habermas YU. Onauchennaya politika i obshchestvennoe mnenie // Tekhnika i nauka kak «ideologiya». M.: Praksis, 2007. S. 136-166. (in Russian).

[10]Guston D. H. Understanding «anticipatory governance» // Social Studies of Science. 2014. Vol. 44, № 2. P. 218-242.

[11]Smorgunov L.V. Institucionalizaciya upravlyaemosti i problema kontrolya $\mathrm{v}$ prostranstve cifrovyh kommunikacij // YUzhno-rossijskij zhurnal social'nyh nauk. 2019. T. 20, № 3. S. 6275. (in Russian). 
[12]Hutchins E. The Cultural Ecosystem of Human Cognition // Philosophical Psychology. 2014. Vol. 27, № 1. P. 34-49.

[13]Conca K. Prospects for a multi-stakeholder dialogue on climate engineering // Environmental Politics. 2019. Vol. 28, № 3. P. 417-440.

[14]Ribeiro B., Shapira P. Anticipating governance challenges in synthetic biology: Insights from biosynthetic menthol // Technological Forecasting and Social Change. 2019. № 139. P. 311320.

[15]Chugunov A.V. Vzaimodejstvie grazhdan $\mathrm{s}$ vlast'yu kak kanal obratnoj svyazi v institucional'noj srede // Vlast'. 2017. № 10. S. 59-66. (in Russian).

[16]Chugunov A.V. Model' elektronnogo upravleniya kak sistema obratnoj svyazi s grazhdanami v koncepcii «Umnyj gorod» // International Journal of Open Information Technologies. 2018. Vol. 6, №.12. S. 106-113. (in Russian).

[17]Kera D.R Anticipatory policy as a design challenge: Experiments with stakeholders engagement in blockchain and distributed ledger technologies (Conference Paper) // Advances in Intelligent Systems and Computing. 2020. Vol. 1010. P. 87-92.

[18]TOP-20 samyh citiruemyh SMI otraslej IT i Telecom - I kvartal 2020] // Medialogiya. URL: https://www.mlg.ru/ratings/media/sectoral/7377 (data obrashcheniya: 23.05.2020). (in Russian).

[19]Renovaciya otnimaet u zhitelej Zyuzino park i podnimaet narod na bunt // Activatica. URL: http://activatica.org/blogs/view/id/9860. (data obrashcheniya: 23.05.2020). (in Russian).

[20]Eksperty o blokchejne i elektronnom golosovanii // ICT Moscow. 13.09.2019. URL: https://ict.moscow/news/blockchain-moscow (data obrashcheniya: 23.05.2020). (in Russian).

[21]Blokchejn $\mathrm{v}$ Rossii: o chem govoryat eksperty. // Mindsmith. URL: https://mindsmith.io/blockchain-experts (data obrashcheniya: 23.05.2020) (in Russian).

[22]Polyakov K. Kak vlasti Moskvy vnedryayut blokchejn v gorodskie proekty // Rusbase. URL: https://rb.ru/opinion/blockchain-moscow/ (data obrashcheniya: 23.05.2020). (in Russian). 